\title{
Manejo de Rebrotes de Digitaria insularis no Plantio Direto de MILHO $^{1}$
}

\author{
Management of Digitaria insularis Sprouts Under No-Till Corn Cultivation
}

TIMOSSI, P.C. ${ }^{2}$

\begin{abstract}
RESUMO - Com a dessecação da vegetação espontânea, nem sempre se consegue obter controle total das espécies daninhas, o que leva à perenização e ao aumento da importância daquelas selecionadas. Em área de plantio direto com predominância de rebrotes de Digitaria insularis, foi testado nicosulfuron isolado $\left(60 \mathrm{~g} \mathrm{ha}^{-1}\right)$ e em mistura em tanque com atrazine $\left(40+1.500 \mathrm{~g} \mathrm{ha}^{-1}\right)$, foramsulfuron + iodosulfuron-methyl $\left(45+3 \mathrm{~g} \mathrm{ha}^{-1}\right)$ e mesotrione em mistura em tanque com atrazine $\left(144+1.500 \mathrm{~g} \mathrm{ha}^{-1}\right)$ sob delineamento de blocos ao acaso, com quatro repetições. Cada parcela apresentava 6 x $4 \mathrm{~m}$, contendo seis linhas de milho. A aplicação dos herbicidas foi feita com pulverizador costal na pressão constante de $30 \mathrm{lbf} \mathrm{pol}^{-2}$, com gasto de 200L ha ${ }^{-1}$ de calda. Foram avaliadas a eficácia e a intoxicação dos herbicidas aos 7, 15 e 30 dias após a aplicação na cultura. Na época da colheita, realizou-se levantamento da cobertura vegetal reinfestante e do seu grau de dificuldade de colheita mecanizada, além da produtividade da cultura. Pode-se inferir que o melhor resultado para o manejo de rebrotes de $D$. insularis foi com a utilização de nicosulfuron isolado a $60 \mathrm{~g} \mathrm{ha}^{-1}$.
\end{abstract}

Palavras-chave: capim-amargoso, controle, plantas daninhas.

ABSTRACT - Total weed control is not always possible under no-till desiccation leading to perennial and increased number of weeds. In no-till cultivation areas with predominant occurrence of Digitaria insularis sprouts, nicosulfuron alone $\left(60 \mathrm{~g} \mathrm{ha}^{-1}\right)$ and in tank mix with atrazine $\left(40+1.500 \mathrm{~g} \mathrm{ha} \mathrm{h}^{-1}\right)$, foramsulfuron + iodosulfuron-methyl $\left(45+3 \mathrm{~g} \mathrm{ha}^{-1}\right)$ and mesotrione in tank mix with atrazine $\left(144+1.500 \mathrm{~g} \mathrm{ha}^{-1}\right)$ were tested in a randomized block design, with four replications. Each plot was $6 \times 4 \mathrm{~m}$, containing six corn culture rows. The herbicides were applied with a back spray at a constant pressure of $30 \mathrm{lbf} \mathrm{pol}^{-2}$, using $200 \mathrm{~L} \mathrm{ha}^{-1}$ solution. Herbicide efficacy and toxicity were evaluated at 7, 15 and 30 days after application. During harvest, reinfesting plant cover and its degree of mechanized harvest were assessed, as well as culture yield. It can be inferred that the best control of $\boldsymbol{D}$. insularis sprouts was obtained with nicosulfuron alone at $60 \mathrm{~g} \mathrm{ha}$.

Keywords: Digitaria insularis, control, weeds.

\section{INTRODUÇÃO}

O manejo das plantas de cobertura nem sempre apresenta controle total, podendo ocorrer rebrotes de algumas espécies da comunidade infestante, além da emergência de plantas daninhas provenientes do banco de sementes, caso haja atraso na semeadura. Uma das espécies que têm sido selecionadas por aplicações frequentes de glyphosate, tanto em áreas de plantio direto como em pomares de frutíferas, é o capimamargoso (Digitaria insularis). Segundo Pitelli \& Durigan (2001), essa espécie é evolutivamente mais adaptada ao sistema plantio direto do que ao convencional, e essa é uma das explicações para o aumento de sua importância relativa nas áreas sob este sistema de cultivo.

1 Recebido para publicação em 24.2.2008 e na forma revisada em 18.2.2009.

2 Prof., Dr., Universidade Estadual de Goiás - UEG, UnU Ipameri, Rod. GO 330, km 241, Anel Viário, $75780-000$ Ipameri-GO, <ptimossi2004@yahoo.com.br>. 
Digitaria insularis é uma espécie perene, herbácea, entoucerada, ereta, rizomatoza, de colmos estriados, com 50 a $100 \mathrm{~cm}$ de altura (Kissmann \& Groth, 1997).

De acordo com Machado et al. (2006), plantas de $D$. insularis provenientes de sementes, ou seja, ainda jovens, apresentam bom controle; em plantas perenizadas e com a presença de rizomas, o controle pelo glyphosate tornase ineficiente. Timossi et al. (2006) mostraram que em plantas já perenizadas, mesmo com doses de até $2,88 \mathrm{~kg} \mathrm{ha}^{-1}$ de glyphosate para o manejo, houve rebrotes.

Em plantio direto sobre vegetação espontânea, tende a agravar o problema de seleção de flora de espécies de difícil controle. A presença de espécies que apresentam rebrote tornase frequente, dificultando a ação dos herbicidas de controle aplicados sobre as culturas, pois são recomendados para o manejo de plantas na fase inicial de crescimento.

As misturas de herbicidas de manejo e de efeito residual auxiliam no manejo de reinfestações pelo banco de sementes do solo, sem, no entanto, contribuir para o manejo daquelas espécies já perenizadas. Segundo Procópio et al. (2006a), o manejo da vegetação espontânea com imazethapyr e chlorimuron-ethyl em mistura em tanque com glyphosate não promoveu sinergismo no controle de $D$. insularis e Leptochloa filiformes. Esses autores constataram ainda que, quando foi adotado o sistema aplique e plante, houve maior incidência de rebrotes dessas espécies, mostrando haver necessidade de pelo menos dois dias para absorção dos herbicidas.

Em áreas de vegetação espontânea, composta principalmente por Digitaria insularis, objetivou-se avaliar a eficácia de herbicidas recomendados para a cultura de milho no controle de rebrotes e reinfestações por plantas daninhas oriundas do banco de sementes do solo.

\section{MATERIAL E MÉTODOS}

$\mathrm{O}$ experimento foi conduzido em área da FEEP - Fazenda Experimental de Ensino e Pesquisa, pertencente à Faculdade de Ciências Agrárias e Veterinárias, Unesp, no município de Jaboticabal-SP.
O delineamento experimental adotado foi o de blocos ao acaso, com cinco tratamentos e quatro repetições. Cada parcela experimental possuía área de $6 \times 4 \mathrm{~m}$, contendo seis linhas da cultura de milho.

O manejo da vegetação espontânea foi realizado 20 dias antes da semeadura do $\mathrm{mi}-$ lho, com o uso de $1,44 \mathrm{~kg} \mathrm{ha}^{-1}$ de glyphosate + $1,005 \mathrm{~kg} \mathrm{ha}^{-1}$ de 2,4-D amina. A aplicação foi feita com pulverizador tratorizado com largura de barra de $12 \mathrm{~m}$ (24 bicos espaçados de 0,5 m), com pontas XR1 1003 à pressão de $30 \mathrm{lbf} \mathrm{pol}^{-2} \mathrm{e}$ consumo de calda equivalente a $250 \mathrm{~L} \mathrm{ha}^{-1}$. A aplicação foi nas seguintes condições atmosféricas: temperatura do ar $=31^{\circ} \mathrm{C}$; umidade relativa $=60 \%$.

A semeadura do milho foi em 23 de dezembro de 2005. Semeou-se o híbrido Triplo Agromen 3150 de ciclo semiprecoce, no espaçamento de $0,9 \mathrm{~m}$. A adubação de semeadura foi feita com $320 \mathrm{~kg} \mathrm{ha}^{-1}$ de 5 - 16 - 10, e a de cobertura, com $300 \mathrm{~kg} \mathrm{ha}^{-1}$ de sulfato de amônio aos 38 dias após a semeadura.

A aplicação de herbicidas para controle dos rebrotes de capim-amargoso e da infestação por plantas daninhas no milho foi feita aos 25 dias após a semeadura (DAS) do milho, com pulverizador costal manual, à pressão constante (mantida pelo $\mathrm{CO}_{2}$ comprimido) de $30 \mathrm{lbf} \mathrm{pol}^{-2}$, munido de barra com seis bicos com pontas XR11002 e consumo de calda equivalente a $200 \mathrm{~L} \mathrm{ha}^{-1}$. As condições atmosféricas obtidas no momento da aplicação, realizada entre $9 \mathrm{~h}$ e $10 \mathrm{~h}$, em 20 de janeiro de 2006, foram: temperatura do ar $\left(29,6{ }^{\circ} \mathrm{C}\right)$, temperatura do solo $\left(28,4^{\circ} \mathrm{C}\right)$, umidade relativa (59\%) e cobertura inexpressiva por nuvens $(5 \%)$. Constataram-se também ventos intermitentes, variando entre 2 e $5 \mathrm{~km} \mathrm{~h}^{-1}$. O solo apresentava-se úmido na superficie. O estágio da cultura do milho, no momento da aplicação dos herbicidas, era de cinco folhas totalmente expandidas.

Os tratamentos herbicidas utilizados para controle dos rebrotes de $D$. insularis e das reinfestações por plantas daninhas na área experimental são apresentados na Tabela 1.

$\mathrm{Na}$ época da aplicação dos herbicidas de controle, além da presença de rebrotes das coberturas vegetais, foi observada a emergência 
de plantas daninhas. Assim, foi feita a determinação da densidade e da composição específica da comunidade infestante. Os dados foram obtidos com o lançamento ao acaso, por cinco vezes, de quadro com dimensões de $0,2 \times 0,5 \mathrm{~m}$, totalizando $0,50 \mathrm{~m}^{2}$ por parcela experimental. Os dados apresentados foram extrapolados para $1 \mathrm{~m}^{2}$.

A avaliação dos possiveis efeitos deletérios dos herbicidas baseou-se na escala de notas do EWRC (1964), a qual é baseada em sintomas visuais e retardo no desenvolvimento, realizada aos 7,15 e 30 DAA. A porcentagem de controle dos rebrotes e das plantas daninhas foi avaliada aos 7, 15 e 30 dias após a aplicação (DAA) dos herbicidas.

$\mathrm{Na}$ época da colheita, foi determinada a porcentagem de cobertura vegetal e o grau de dificuldade para a realização desta, além de se determinar a produtividade da cultura. Para classificar o grau de dificuldade proporcionado pela comunidade reinfestante, adotou-se a escala de notas observada na Tabela 2.

Quando necessário, os dados obtidos foram submetidos à análise de variância; para a comparação das médias, utilizou-se o teste de Tukey a $5 \%$ de probabilidade.

Tabela 1 - Herbicidas utilizados para controle de rebrotes de Digitaria insularis e reinfestações por plantas daninhas. Jaboticabal-SP

\begin{tabular}{|l|c|}
\hline \multicolumn{1}{|c|}{ Herbicida } & $\begin{array}{c}\text { Dosagem } \\
\left(\mathrm{g} \mathrm{ha}^{-1}\right)\end{array}$ \\
\hline Nicosulfuron $(\mathrm{N})$ & 60 \\
\hline Nicosulfuron + atrazine $(\mathrm{N}+\mathrm{A})$ & $40+1.500$ \\
\hline Foramsulfuron + iodosulfuron-methyl ${ }^{1 /}(\mathrm{F}+\mathrm{I})$ & $45+3$ \\
\hline Mesotrione $^{2 /}+$ atrazine $(\mathrm{M}+\mathrm{A})$ & $144+1.500$ \\
\hline Testemunha $(\mathrm{T})$ & --- \\
\hline
\end{tabular}

1/ Adição de $0,5 \% \mathrm{v} / \mathrm{v}$ do adjuvante Hoefix ; ${ }^{2 /}$ Adição de $0,5 \%$ v/v de Assist.

Tabela 2 - Classificação da dificuldade de colheita mecanizada da cultura. Jaboticabal, 2007

\begin{tabular}{|c|l|}
\hline Nota & \multicolumn{1}{|c|}{ Grau de dificuldade da colheita } \\
\hline 1 & Fácil - praticamente sem plantas daninhas \\
\hline 2 & Fácil - com presença de plantas daninhas de pequeno porte \\
\hline 3 & Moderado - presença de resíduos de plantas daninhas nos grãos \\
\hline 4 & Difícil - presença de plantas daninhas com grande porte e trepadeiras \\
\hline 5 & Bastante difícil - interrupção contínua à impossibilidade de colheita \\
\hline
\end{tabular}

\section{RESULTADOS E DISCUSSÃO}

A massa vegetal seca proveniente da cobertura vegetal de capim-amargoso foi de 4,6 t ha ${ }^{-1}$, sendo constatada baixa influência na supressão da emergência de plantas daninhas provenientes do banco de sementes.

$\mathrm{Na}$ época da aplicação dos herbicidas de controle, havia cerca de $80 \%$ de cobertura vegetal proporcionada pelos rebrotes de capimamargoso, espécie-alvo deste estudo, além de plantas de apaga-fogo (Alternanthera tenella) com até seis folhas e de capim-carrapicho (Cenchrus echinatus) com até dois perfilhos. A densidade dessas últimas espécies foi de 115 plantas $\mathrm{m}^{-2}$, sendo $64 \%$ de apaga-fogo e $33 \%$ de capim-carrapicho.

Os herbicidas testados para o manejo dessas espécies estão entre os mais recomendados para controle de plantas daninhas na cultura do milho. Segundo Rizzardi et al. (2004), as triazinas e as sulfoniluréias são os grupos químicos de herbicidas mais utilizados na cultura, controlando amplo espectro de monocotiledôneas e dicotiledôneas.

Na Tabela 3 são apresentadas as médias da porcentagem de controle dos rebrotes de D. insularis. Verifica-se que aos 7 e 15 DAA os melhores resultados de controle são obtidos com a aplicação de mesotrione + atrazine. No entanto, embora com baixo nivel de controle na primeira época, constata-se que a aplicação de nicosulfuron isolado mostrou bom resultado no final das avaliações (30 DAA). Pôde-se observar, nas épocas avaliadas, que os herbicidas não foram capazes de controlar totalmente os rebrotes de capim-amargoso, porém retardaram o seu crescimento, possibilitando o desenvolvimento da cultura. O menor controle no final das avaliações foi obtido com a aplicação de nicosulfuron + atrazine, mostrando a necessidade da utilização de maior concentração da molécula para obter boas médias de controle. Procópio et al. (2006b) obtiveram bons resultados de controle de Digitaria insularis e Leptochloa filiformes quando fizeram aplicação sequencial de glyphosate e paraquat+diuron em pré-semeadura de soja.

Além dos rebrotes da cobertura vegetal de capim-amargoso, havia também, em menores proporções, reinfestações de apaga-fogo e 
capim-carrapicho. As médias das porcentagens de controle de apaga-fogo são apresentadas na Tabela 4. O melhor resultado de controle, logo aos 7 DAA, é obtido com a aplicação das misturas de nicosulfuron e mesotrione com atrazine.

Aos 15 DAA, verifica-se que a mistura de nicosulfuron + atrazine melhorou sua eficácia, atingindo controle total da espécie, enquanto a mistura de mesotrione com atrazine diminuiu a eficácia. Já aos 30 DAA, apenas a aplicação da mistura de mesotrione + atrazine apresentou menor eficácia no controle de apaga-fogo. Os demais herbicidas mostraram boa eficácia para o controle dessa planta daninha.

Para o capim-carrapicho, o melhor patamar aos 7 DAA foi obtido com a aplicação das misturas herbicidas (Tabela 5). Aos 15 e 30 DAA, nota-se que houve aumento progressivo na eficácia dos herbicidas, exceto para mesotrione + atrazine, que apresentou decréscimo na porcentagem de controle dessa planta daninha.

Tabela 3 - Médias das porcentagens de controle de rebrotes de Digitaria insularis, atribuídas visualmente aos 7, 15 e 30 dias após a aplicação (DAA)

\begin{tabular}{|l|c|c|c|}
\hline \multirow{2}{*}{ Herbicida } & \multicolumn{3}{c|}{ Época de avaliação } \\
\cline { 2 - 4 } & 7 DAA & 15 DAA & 30 DAA \\
\hline Nicosulfuron & $41,3 \mathrm{c}$ & $77,5 \mathrm{~b}$ & $81,3 \mathrm{a}$ \\
\hline Nicosulfuron + atrazine & $50,0 \mathrm{bc}$ & $62,5 \mathrm{c}$ & $42,5 \mathrm{~b}$ \\
\hline Foramsulfuron + iodosulfuron-methyl & $52,5 \mathrm{~b}$ & $72,5 \mathrm{~b}$ & $53,8 \mathrm{ab}$ \\
\hline Mesotrione + atrazine & $66,3 \mathrm{a}$ & $91,3 \mathrm{a}$ & $70,0 \mathrm{ab}$ \\
\hline Testemunha & $0,0 \mathrm{~d}$ & $0,0 \mathrm{~d}$ & $0,0 \mathrm{c}$ \\
\hline F & $103,67 * *$ & $263,09 * *$ & $21,35 * *$ \\
\hline CV & 11,8 & 7,2 & 27,5 \\
\hline DMS & 11,1 & 9,9 & 30,7 \\
\hline
\end{tabular}

Letras iguais, na mesma coluna, não diferem entre si pelo teste de Tukey a $5 \%$ de probabilidade.

Tabela 4 - Médias das porcentagens de controle de apaga-fogo (Alternanthera tenella), atribuídas visualmente aos 7, $15 \mathrm{e}$ 30 dias após a aplicação (DAA)

\begin{tabular}{|l|c|c|c|}
\hline \multirow{2}{*}{ Herbicida } & \multicolumn{3}{c|}{ Época de avaliação } \\
\cline { 2 - 4 } & 7 DAA & 15 DAA & 30 DAA \\
\hline Nicosulfuron & $63,8 \mathrm{~b}$ & $83,8 \mathrm{~b}$ & $97,8 \mathrm{a}$ \\
\hline Nicosulfuron + atrazine & $95,8 \mathrm{a}$ & $100,0 \mathrm{a}$ & $100,0 \mathrm{a}$ \\
\hline Foramsulfuron + iodosulfuron-methyl & $72,5 \mathrm{~b}$ & $86,2 \mathrm{~b}$ & $95,3 \mathrm{a}$ \\
\hline Mesotrione + atrazine & $91,2 \mathrm{a}$ & $67,5 \mathrm{c}$ & $71,3 \mathrm{~b}$ \\
\hline Testemunha & $0,0 \mathrm{c}$ & $0,0 \mathrm{~d}$ & $0,0 \mathrm{c}$ \\
\hline F & $250,09 * *$ & $586,18^{* *}$ & $216,96^{* *}$ \\
\hline CV & 7,5 & 4,8 & 7,9 \\
\hline DMS & 11,0 & 7,4 & 13,0 \\
\hline
\end{tabular}

Letras iguais, na mesma coluna, não diferem entre si pelo teste de Tukey a $5 \%$ de probabilidade.
Tabela 5 - Médias das porcentagens de controle de capimcarrapicho (Cenchrus echinatus), atribuídas visualmente aos 7, 15 e 30 dias após a aplicação (DAA)

\begin{tabular}{|l|c|c|c|}
\hline \multirow{2}{*}{\multicolumn{1}{|c|}{ Herbicida }} & \multicolumn{3}{c|}{ Época de avaliação } \\
\cline { 2 - 4 } & 7 DAA & 15 DAA & 30 DAA \\
\hline Nicosulfuron & $65,0 \mathrm{bc}$ & $86,3 \mathrm{a}$ & $98,0 \mathrm{a}$ \\
\hline Nicosulfuron + atrazine & $77,5 \mathrm{a}$ & $86,3 \mathrm{a}$ & $92,3 \mathrm{a}$ \\
\hline Foramsulfuron + iodosulfuron-methyl & $61,3 \mathrm{c}$ & $72,5 \mathrm{a}$ & $89,5 \mathrm{a}$ \\
\hline Mesotrione + atrazine & $72,5 \mathrm{ab}$ & $47,5 \mathrm{~b}$ & $32,5 \mathrm{~b}$ \\
\hline Testemunha & $0,0 \mathrm{~d}$ & $0,0 \mathrm{c}$ & $0,0 \mathrm{c}$ \\
\hline F & $244,69^{* *}$ & $118,97 * *$ & $125,33^{*} *$ \\
\hline CV & 7,3 & 11,4 & 12,5 \\
\hline DMS & 9,1 & 15,0 & 17,6 \\
\hline
\end{tabular}

Letras iguais, na mesma coluna, não diferem entre si pelo teste de Tukey a $5 \%$ de probabilidade.

Foramsulfuron + iodosulfuron-methyl e nicosulfuron isolado e em mistura com atrazine apresentaram praticamente a mesma eficácia de controle em se tratando de capimcarrapicho.

Quanto à intoxicação de plantas de milho promovida pela aplicação dos herbicidas, avaliadas segundo escala de notas do EWRC, constatou-se maior intoxicação, aos 7 DAA, com a aplicação de foramsulfuron + iodosulfuron-methyl, atingindo efeito moderado $(3,8)$. Segundo Damião Filho et al. (1996), herbicidas inibidores da ALS podem causar toxicidade diferencial em híbridos de milho. No entanto, a partir dos 15 DAA, não foram observados, visualmente, efeitos da intoxicação causados pelos herbicidas.

Na época da colheita do milho, foi feita avaliação da porcentagem de cobertura vegetal viva proveniente da reinfestação da área, após a aplicação dos herbicidas de controle. Também, realizou-se a avaliação do grau de dificuldade de colheita mecanizada imposto pelas reinfestações (Figura 1). Observa-se no histograma que a aplicação de nicosulfuron, isolado e em mistura com atrazine, apresentou os melhores resultados, mantendo a área praticamente no limpo. A manutenção da área agrícola no limpo até a época de colheita é importante para o manejo do banco de sementes de plantas daninhas da área. Tanto foramsulfuron + iodosulfuron-methyl quanto mesotrione + atrazine possibilitaram o desenvolvimento da comunidade infestante, chegando na época da colheita com infestação parcial da área. No entanto, nenhum dos tratamentos herbicidas permitiu o crescimento da comunidade infestante a ponto de interferir 
em uma possivel colheita mecanizada da cultura do milho. Jakelaitis et al. (2004) mostraram que a utilização de subdoses de nicosulfuron auxilia na formação de pastagem pelo sistema integração lavoura-pecuária, inibindo o desenvolvimento de Brachiaria brizantha e possibilitando boa produtividade de milho.

No tocante à produtividade da cultura, pode-se observar, na Figura 2, que os tratamentos herbicidas diminuíram a interferência negativa das plantas daninhas. A maior média de produtividade foi atingida com uso de nicosulfuron isolado, sem, no entanto, diferir significativamente dos demais tratamentos herbicidas. A comunidade infestante, em comparação a este herbicida, causou redução de $31,4 \%$ no potencial produtivo da cultura.

Embora todos os herbicidas tenham apresentado bons resultados de controle das plantas daninhas, pode-se inferir que a melhor

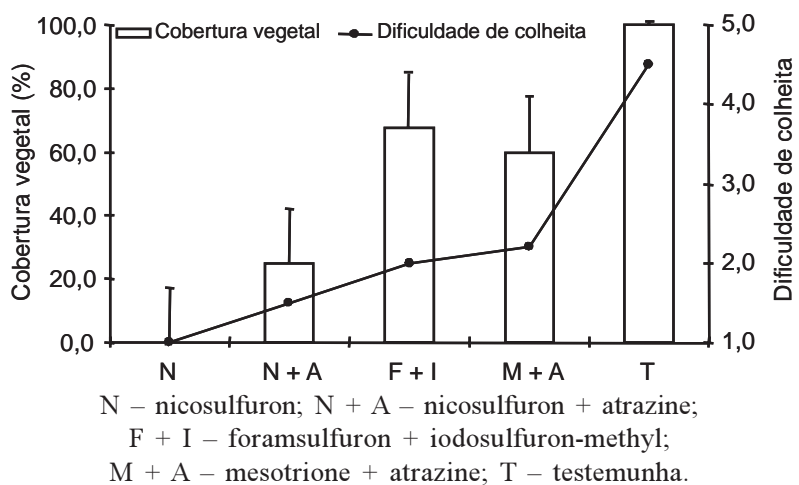

Figura 1 - Médias da porcentagem de cobertura vegetal e dificuldade de colheita ocasionada por esta, nos tratamentos herbicidas. Jaboticabal-SP, 2005.

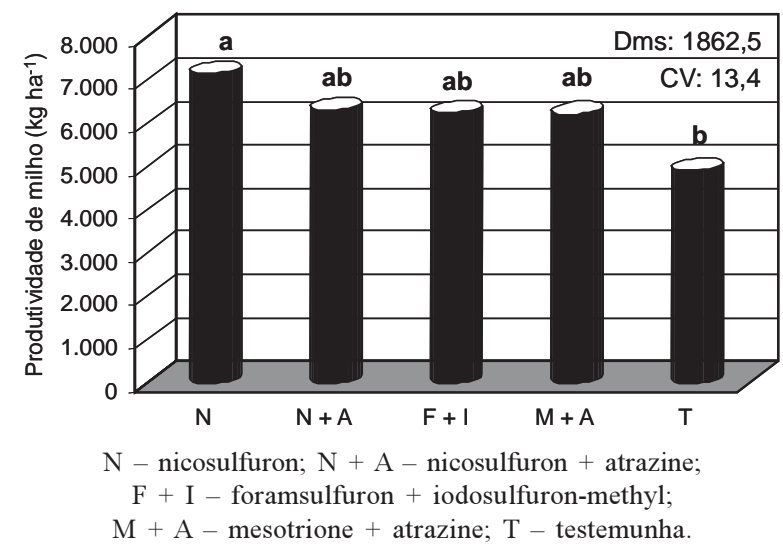

Figura 2 - Médias da produtividade de grãos de milho, quando submetidos aos herbicidas pesquisados. Jaboticabal-SP, 2005 recomendação para o manejo da comunidade infestante - onde há maior cobertura por rebrotes de capim-amargoso - foi com a utilização de nicosulfuron isolado a 60,0 g i.a. ha ${ }^{-1}$.

\section{AGRADECIMENTOS}

Ao Técnico Agrícola Gilson José Leite, pelo auxílio na obtenção dos dados em campo; à Ishihara Brasil Defensivos Agrícola LTDA, pelo financiamento da pesquisa; e à FEEP/UNESP, pela concessão e manutenção da área experimental.

\section{LITERATURA CITADA}

DAMIÃO FILHO, C. F.; MÔRO, F. V.; TAVEIRA, L. R. Respostas de híbridos de milho a nicosulfuron. 1- Aspectos biológicos e da produção. Planta Daninha, v. 14, n. 1, p. 3-13, 1996.

EUROPEAN WEED RESEARCH COUNCIL - EWRC Report of the $3^{\text {rd }}$ and $4^{\text {th }}$ meetings of EWRC. Cittee of methods in weed research. Weed Res., v. 4, n. 1, p. 88, 1964.

JAKELAITIS, A. et al. Efeitos de herbicidas no consórcio de milho com Brachiaria brizantha. Planta Daninha, v. 23, n. 1, p. 69-78, 2005

KISSMANN, K. G; GROTH, D. Plantas infestantes e nocivas. São Paulo: BASF Brasileira, 1997. p. 675-678. Tomo I

MACHADO, A. F. L. et al. Análise de crescimento de Digitaria insularis. Planta Daninha, v. 24, n. 1, p. 641-647, 2006.

PITELLI, R. A.; DURIGAN, J. C. Ecologia das plantas daninhas no sistema de plantio direto. In: ROSSELO, R. D. Siembra Directa en el Cono Sur. Montevideo: Procisur, 2001. v. 1. p. 203-210.

PROCÓPIO, S. O. et al. Eficácia de imazethapyr e chlorimuron-ethyl em aplicações de pré-semeadura da cultura da soja. Planta Daninha, v. 24, n. 3, p. 467-73, 2006 a.

PROCÓPIO, S. O. et al. Efeito de dessecantes no controle de plantas daninhas na cultura da soja. Planta Daninha, v. 24, n. 1, p. 193-197, 2006b.

RIZZARDI, M. A.; KARAM, D.; DA CRUZ, M. B. Manejo e controle de plantas daninhas em milho e sorgo. In: VARGAS, L.; ROMAN, E. S. (Eds.). Manual de manejo e controle de plantas daninhas. Bento Gonçalves: Embrapa Uva e Vinho, 2004. p. 571-594

TIMOSSI, P. C.; LEITE, G. J.; DURIGAN, J. C. Eficácia de glyphosate em plantas de cobertura. Planta Daninha, v. 24, n. 3, p. $475-480,2006$. 